\title{
Naltrexone Reduces Ethanol- and/or Water-Reinforced Responding in Rhesus Monkeys: Effect Depends Upon Ethanol Concentration
}

\author{
Keith L. Williams and James H. Woods
}

\begin{abstract}
Background: The opioid antagonist naltrexone reduces responding for ethanol. If naltrexone produces this cffect by blocking ethanol-induced opioid activity, then naltrexone should reduce responding for ethanol regardless of level of the ethanol responding relative to an alternatively available reinforcer. In addition, if naltrexone competitively blocks ethanol-induced opioid activity, then the naltrexone effect may be surmountable by increasing ethanol concentration and, thus, ethanol intake $(\mathrm{g} / \mathrm{kg})$. This study was conducted to determine whether naltrexone will selectively reduce ethanol-reinforced responding when the ethanol concentration is varied such that ethanol fluid deliveries are less than, greater than, or equal to the fluid deliveries of concurrently available water.

Methods: Four adult male rhesus monkeys were allowed to respond for ethanol or water concurrently for $2 \mathrm{hr}$ per day. Ethanol concentration was either $2 \%, 8 \%$, or $32 \%$. On various days, either saline or naltrexone $(0.1 \mathrm{mg} / \mathrm{kg})$ was given intramuscularly $30 \mathrm{~min}$ before the drinking session.

Results: When ethanol fluid deliveries were greater than those of water (at $2 \%$ ethanol), naltrexone reduced responding for ethanol. When the ethanol and water fluid deliveries were approximately equal (at $8 \%$ ethanol), naltrexone reduced both ethanol and water fluid deliveries. When water fluid deliveries were greater than those of ethanol (at $32 \%$ ethanol), naltrexone reduced responding for water.

Conclusions: Thus, naltrexone reduced responding for the preferred fluid, either ethanol or water, depending on ethanol concentration. The effect was not surmountable by increasing ethanol concentration and, therefore, ethanol intake $(\mathrm{g} / \mathrm{kg})$. Naltrexone may reduce ethanol-reinforced responding by a mechanism other than that of blocking ethanol-induced opioid activity. Naltrexone may be inducing an aversive interoceptive state.
\end{abstract}

Key Words: Opiate Antagonists, Drinking, Alcohol, Operant Responding, Preference.

$\mathbf{T}$ THE OPIOID ANTAGONIST naltrexone (NTX), in some conditions, selectively reduces ethanol-related behaviors (responding for or consumption of ethanol). If increased endogenous opioid activity modulates ethanol's reinforcing properties, opioid receptor blockade should reduce ethanol drinking regardless of the fluid volume consumed relative to a concurrently available reinforcer. For example, in one study, the opioid antagonist naloxone selectively reduced ethanol drinking even when the rats were consuming less ethanol than water during baseline conditions (Marfaing-Jallat et al., 1983). After behavioral manipulations were performed to increase ethanol consumption relative to water, naloxone continued to reduce ethanol drinking selectively. When ethanol drinking was less than that of water in another study, naloxone, at high

From the Departments of Psychology (K.L.W., J.H.W.) and Pharmacology (J.H.W.), University of Michigan, Ann Arbor, Michigan.

Received for publication February 12, 1999; accepted June 21, 1999.

This work was supported by USPHS Grant AA-11424.

Reprint requests: Keith Williams, 1301 MSRB III, Department of Pharmacology, University of Michigan, Ann Arbor, MI 48109-0632; Fax: 734-7647118; E-mail: keithwil@umich.edu

Copyright $(\odot) 1999$ by the Research Society on Alcoholism. doses, reduced only ethanol drinking (Froehlich et al., 1990). In rats in which responding for ethanol exceeded that for water, naloxone reduced responding for ethanol without affecting responding for water (Samson and Doyle, 1985). In addition, the naloxone doses that reduced responding for ethanol failed to reduce responding for sucrose when it was offered concurrently with water. In a previous study (Williams et al., 1998), we showed, in monkeys, that NTX reduced responding for ethanol in a doserelated manner. Opioid antagonists, therefore, appear to have selective effects on ethanol-related behaviors in some situations.

NTX, in other conditions, fails to reduce ethanol-related behaviors selectively. For example, one study examined the effects of NTX on 24-hr free access to food, water, and ethanol (Myers et al., 1986). In that study, NTX injections reduced ethanol drinking when compared with ethanol drinking after saline injections. However, food and total fluid intake (both ethanol and water) were reduced as well. In another study with free access conditions in monkeys, NTX reduced both the ethanol and water drinking within the first $2 \mathrm{hr}$ after the injection (Kornet et al., 1991). When the fluids were measured more than $12 \mathrm{hr}$ after the NTX 
injection, ethanol consumption was still reduced and the water consumption was no different from that after saline. Thus, in some experimental conditions, NTX failed to reduce ethanol drinking selectively. Because these experiments differ from those in the preceding paragraph in many ways, it is difficult to determine which variables modulate the expression of the NTX effect.

The purpose of this study was to examine the effect of N'TX on conditions in which the relative responding for ethanol and water was altered by manipulating the ethanol concentration. In a previous study (Williams et al., 1998), we showed that responding for ethanol was greater than that for water at low ethanol concentrations (e.g., $1 \%$ and $2 \%$ ). At $8 \%$ ethanol, responding for ethanol was approximately equal to that of water. At even higher ethanol concentrations (32\%), responding for water surpassed that for ethanol (unpublished data). Although the ethanol fluid deliveries decreased at concentrations higher than $4 \%$ ethanol, the intake appeared to plateau at $1.5 \mathrm{~g} / \mathrm{kg}$ at concentrations from $4 \%$ to $32 \%$. We wanted to test NTX in conditions where responding for ethanol was less than, greater than, or equal to responding for the concurrently available water. If NTX reduces ethanol-reinforced responding by blocking the endogenous opioid activation, then NTX should selectively reduce ethanol fluid deliveries even if the number of fluid deliveries was equal to or less than the concurrently available water. In addition, if NTX competitively blocks ethanol reinforcement, then monkeys with access to higher ethanol concentrations might substantially increase their ethanol intake to surmount the antagonist effect in a manner similar to that of an opioid agonist/ competitive antagonist interaction (Rowlett et al., 1998; Winger et al., 1992).

\section{MATERIALS AND METHODS}

\section{Subjects}

Subjects were four adult male rhesus monkeys (Macaca mulatta; weighing $6.1-9.0 \mathrm{~kg}$ ) maintained at approximately $80 \%$ of their free-feeding weights. All of the monkeys had extensive experience, responding for oral ethanol fluid deliveries. In these experiments, the Guide for the Care and Use of Laboratory Animals (NIH publication, volume 25, number 28, revised 1996) was followed.

\section{Apparatus}

The animal housing room was on a 12-hr light/dark cycle (lights on at $0630 \mathrm{hr}$, lights off at $1850 \mathrm{hr}$ ). The monkeys were housed in individual cages measuring $64 \times 72 \times 85-\mathrm{cm}$ high. A fluid-delivery panel, similar to that used in other studies (Meisch et al., 1975; Williams et al., 1998), was attached to one wall of each cage during daily sessions. Holes were cut in the cage wall so that two brass spouts on the fluid-delivery panel protruded into the cage $50 \mathrm{~cm}$ from the floor. A stimulus light that could be illuminated red or green was located $3 \mathrm{~cm}$ above each spout. The drinking solutions were contained in 1000-ml plastic bottles attached to the back of the panel. Plastic tubing connected each bottle to the spout valve. The fluid containers were elevated so that the liquid was gravity-fed to the spout valve and delivery was controlled by a solenoid switch. Contact with either spout closed an electrical circuit (drinkometer) and a response was recorded. The stimulus light above the spout flashed when contact was made with the spout. When the reinforcement schedule was satisfied, the solenoid was activated and $0.5 \mathrm{ml}$ of fluid was delivered. Solutions were measured after the session by using graduated cylinders to confirm delivery amounts. The experiments were controlled and the data recorded by using IBM PCjr microcomputers located in a room adjacent to the housing room.

\section{Procedure}

Experimental sessions were conducted every day. Each session lasted 2 $\mathrm{hr}$, during which the animal could respond and obtain either ethanol or concurrently available water. Both ethanol and water were available under the green stimulus light. The monkeys were reinforced with $0.5 \mathrm{ml}$ of fluid for every mouth contact on the spout (continuous reinforcement, or a fixed ratio of 1). Water was always available from one of the spouts. The animals were fed after the session.

The ethanol concentration-effect curve was replicated in these monkeys before opioid antagonist administrations. The ethanol concentrations were tested in an ascending order from $1 \%$ to $32 \%$. Each concentration was determined for 5 to 7 days before increasing to the next concentration. After determining the concentration-effect curve, the antagonist pretreatments were tested after responding for the $32 \%$ ethanol and concurrently available water. Injections of saline or NTX $(0.1 \mathrm{mg} / \mathrm{kg})$ were given $30 \mathrm{~min}$ before the experimental sessions. In each monkey, NTX was tested twice, with a week between each injection. Saline injections were given twice between each antagonist injection day. After antagonist testing was complete at $32 \%$ ethanol, the monkeys received access to $2 \%$ ethanol for a week before antagonist testing. A similar regimen was then completed for $8 \%$ ethanol. At $8 \%$, NTX was tested an additional two times because the variability was high during baselines and after saline injections.

\section{Drugs}

Ethanol solutions were prepared by mixing appropriate volumes of $95 \% \mathrm{w} / \mathrm{v}$ ethanol and tap water. Naltrexone hydrochloride was supplied by the National Institute of Drug Abuse and mixed with sterile water to prepare the appropriate concentrations.

\section{Data Analysis}

Each monkey's average fluid deliveries and ethanol intake, in grams per kilogram $(\mathrm{g} / \mathrm{kg})$, were used to calculate the mean and standard error of the mean (SEM) for the group of monkeys. Each monkey's data, at $2 \%$ and $32 \%$, were calculated by averaging approximately 10 to 14 noninjection "baseline" days, 6 saline injection days, or 2 NTX injection days. At $8 \%$ ethanol, approximately 21 baseline days, 8 saline injection days, or 4 NTX injection days were used to calculate each monkey's average. The data are presented as mean and SEM values of the group data.

The fluid-delivery data for the ethanol concentration-effect curve were analyzed by using a two-way repeated measures ANOVA [solution (2) $\times$ concentration (6)]. The fluid-delivery data for the NTX testing at $2 \%, 8 \%$, and $32 \%$ ethanol were analyzed individually by using two-way repeated measures ANOVA [solution (2) $\times$ condition (3)]. One-way repeated measures ANOVA was used to separately analyze the ethanol intake $(\mathrm{g} / \mathrm{kg})$ data for the concentration-effect curve, as well as NTX testing at $2 \%, 8 \%$, and $32 \%$ ethanol. Subsequent to each ANOVA, a post hoc Student-Newman-Keuls (SNK) test was performed for individual comparisons.

The cumulative record data were collected as the total fluid deliveries per 5-min period. The cumulative record data for the animal shown in Fig. 5 were representative of the data collected in the other animals.

\section{RESULTS}

The concentration of ethanol determined whether ethanol or water maintained the greater number of fluid deliveries (Fig. 1, top). At 1\%, 2\%, and 4\%, ethanol maintained 

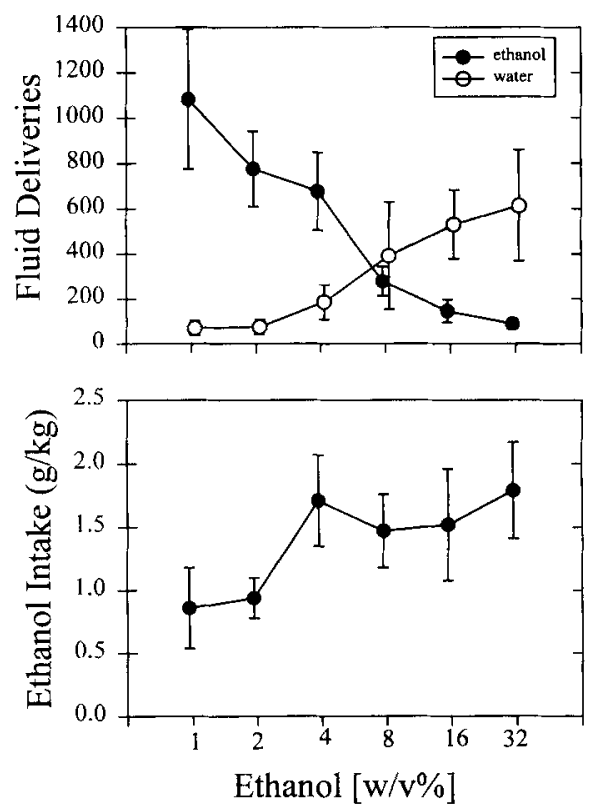

Fig. 1. (Top) Average number of fluid deliveries for ethanol (๑) and concurrently available water $(O)$ as the concentration of ethanol varied from $1 \%$ to $32 \%$. (Bottom) shows the average intake in grams per kilogram $(\mathrm{g} / \mathrm{kg})$ as ethanol concentration varied $(\Theta)$. The points represent the overall average with the standard error $(n=4)$.

more fluid deliveries than the concurrently available water [interaction of solution and ethanol concentration, $F(5,15)=9.11 ; p<0.001]$. However, the only significant difference between ethanol and water fluid deliveries existed at $1 \%$ (SNK, $p<0.02)$. At $8 \%$, ethanol and water maintained approximately the same number of fluid deliveries. At $16 \%$ and $32 \%$ ethanol, the fluid deliveries of water were greater than those of ethanol, although these effects did not reach statistical significance. The ethanol intake (Fig. 1, bottom) was approximately $1 \mathrm{~g} / \mathrm{kg}$ at both $1 \%$ and $2 \%$ ethanol. Thereafter, the ethanol intake was equal to or greater than $1.5 \mathrm{~g} / \mathrm{kg}$. The effect of ethanol concentration on ethanol intake $(\mathrm{g} / \mathrm{kg})$ was significant $[F(5,15)=3.01$; $p<0.05$ ], but the post hoc SNK failed to reveal which concentrations were different.

When NTX $0.1 \mathrm{mg} / \mathrm{kg}$ was given before access to $2 \%$ ethanol and water (Fig. 2, top), NTX primarily affected responding for ethanol. There was a main effect of solution $[F(1,3)=17.6 ; p<0.02]$, a main effect of condition $[F(2,6)=18.3 ; p<0.003]$, and an interaction of solution and condition $[F(2,6)=6.59 ; p<0.03]$. During baseline and after saline injection, ethanol maintained more fluid deliveries than did water (SNK, $p<0.002$ and $p<0.002$, respectively). After NTX pretreatment, only the ethanol fluid deliveries were reduced compared with those at baseline (SNK, $p<0.004)$ and after saline pretreatment (SNK, $p<0.004$ ). Ethanol intake (Fig. 2, bottom) after NTX administration was also reduced compared with baseline (SNK, $p<0.004$ ) and after saline pretreatment (SNK, $p<$ $0.004)$. Water fluid deliveries were unaffected by NTX administration.
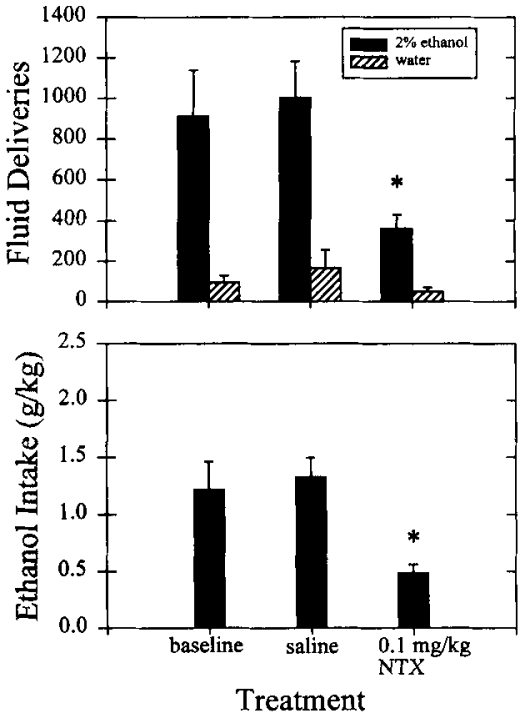

Fig. 2. (Top) Average number of fluid deliveries of $2 \%$ ethanol $(\square$ ) and concurrently available water (2), after three different pretreatments, i.e., noninjection baseline, saline, and naltrexone (NTX; $0.1 \mathrm{mg} / \mathrm{kg}$ ). (Bottom) Average ethanol intake $(g / \mathrm{kg})$ after the same pretreatments. The bars represent the average with the standard error $(n=4)$. " indicates a significant difference from saline $(p<$ 0.05 ).
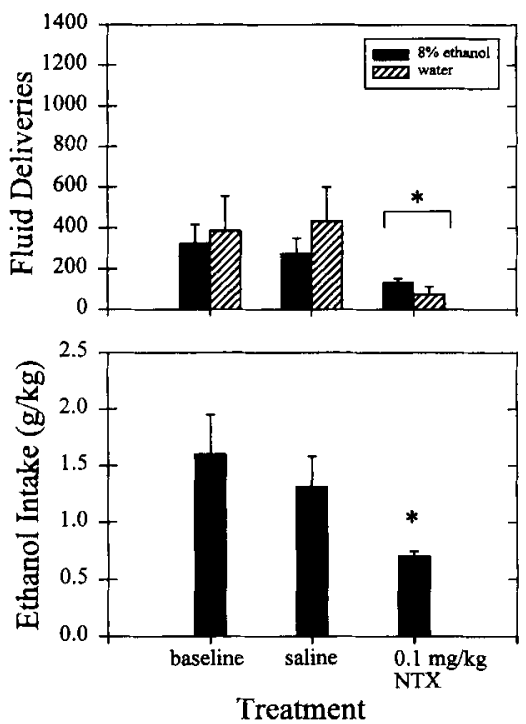

Fig. 3. (Top) Average number of fluid deliveries of $8 \%$ ethanol ( $\square$ ) and concurrently available water (2), after three different pretreatments, i.e., noninjection baseline, saline, and naitrexone (NTX; $0.1 \mathrm{mg} / \mathrm{kg}$ ). (Bottom) Average ethanol intake $(\mathrm{g} / \mathrm{kg})$ after the same pretreatments. The bars represent the average with the standard error $(n=4) .{ }^{*}$ indicates a significant difference from saline $(p<$ 0.05).

At $8 \%$ ethanol, the ethanol and water fluid deliveries were approximately the same at baseline and after saline administration (Fig. 3, top). The main effect of solution and the interaction effect of solution and condition were not significant ( $p=0.69$ and $p=0.49$, respectively). However, there was a main effect of condition $[F(2,6)=6.49 ; p<$ $0.04]$, for which the post hoc SNK showed that total fluid deliveries (ethanol and water) after NTX were significantly less than those at baseline $(p<0.05)$ or after saline pre- 

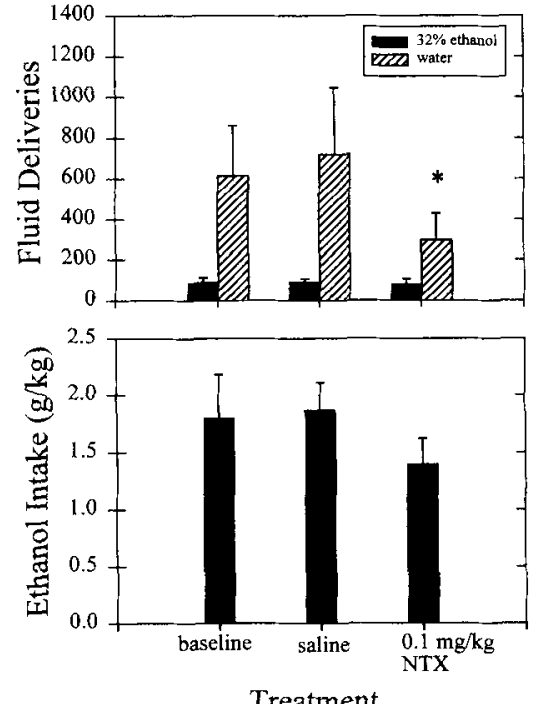

Fig. 4. (Top) Average number of fluid deliveries of $32 \%$ ethanol $(\square)$ and concurrently available water (2a), after three different pretreatments, i.e., noninjection baseline, saline, and naltrexone (NTX; $0.1 \mathrm{mg} / \mathrm{kg}$ ). (Bottom) Average ethanol intake $(\mathrm{g} / \mathrm{kg})$ after the same pretreatments. The bars represent the average with the standard error $(n=4)$. " indicates a significant difference from saline $(p<$ 0.05).

treatment $(p<0.03)$. Ethanol intake after NTX (Fig. 3, bottom) was also reduced below that of baseline (SNK, $p<$ 0.02 ) or after saline pretreatment (SNK, $p<0.04$ ).

When NTX $0.1 \mathrm{mg} / \mathrm{kg}$ was given before access to $32 \%$ ethanol and water (Fig. 4, top), there was a significant main effect of NTX $[F(2,6)=5.25 ; p<0.05]$. The main effect of solution, as well as the interaction effect of solution and condition, failed to reach significance $(p=0.13$ and $p=$ 0.12 , respectively). However, the post hoc SNK revealed that the water fluid deliveries exceeded those of ethanol at baseline $(p<0.02)$ and after saline pretreatment $(p<$ 0.01 ). In addition, the water fluid deliveries after NTX pretreatment were significantly less than those after baseline $(p<0.05)$ or after saline pretreatment $(p<0.04)$. Ethanol fluid deliveries and intake were unaffected by NTX administration at this concentration of ethanol (Fig. 4 , bottom).

In Fig. 5, cumulative record data for a representative monkey are shown. The data recorded after a saline injection at $2 \%, 8 \%$, and $32 \%$ ethanol are compared with the data recorded after an NTX injection at the same ethanol concentrations. The ordinate scales are different at each ethanol concentration to show the data in a clearer manner. These data show the relationship of the fluid deliveries obtained for ethanol versus water across the various ethanol concentrations. Most fluid deliveries, regardless of whether they were ethanol or water, were obtained early in the session. The differences in drug intake $(\mathrm{g} / \mathrm{kg})$, shown in the upper right corner of each panel, resulted from the pattern of responding throughout the session. For example, after a saline injection, this monkey responded substantially more for ethanol at $2 \%$ than for the ethanol at $8 \%$ or $32 \%$, although the drug intakes for the entire sessions were quite similar (upper panels). Although this cumulative record shows some periods where water fluid deliveries increased during or shortly after an increase in ethanol fluid deliveries, this pattern was not observed consistently across the different monkeys. After $0.1 \mathrm{mg} / \mathrm{kg}$ NTX (bottom panels), the fluid deliveries of ethanol and/or water were reduced only after the first 5-min bin regardless of whether the ethanol concentration was $2 \%, 8 \%$, or $32 \%$.

\section{DISCUSSION}

Ethanol concentration determined whether ethanol or water maintained the greater number of fluid deliveries, and the effect of NTX appeared to be selective for the fluid that maintained the greater number of deliveries. When the fluid deliveries of ethanol were greater than those of water (at $2 \%$ ethanol), NTX reduced only ethanol fluid deliveries. When the fluid deliveries of ethanol were approximately equal to those of water (at 8\% ethanol), NTX reduced fluid deliveries of both ethanol and water nonselectively. When the fluid deliveries of ethanol were less than those of water (at $32 \%$ ethanol), NTX reduced only the water fluid deliveries. Thus, NTX reduced, responding for the fluid that maintained the greater amount of fluid deliveries.

NTX reduced the fluid deliveries of the solution that maintained the greater amount of fluid deliveries regardless of ethanol intake. Thus, when the experimental variables were changed (i.e., ethanol concentration), the NTX effect was altered. Different experimental variables may explain the discrepancy between studies that show ethanolselective effects of NTX and studies that fail to show ethanol-selective effects. An explanation for the observations in our study may be that endogenous opioid activity modulates the rewarding qualities of the avid responding for or the consumption of the preferred reinforcer, either ethanol or water. The actual act of responding or consuming may have qualities that are affected by opioid antagonism. Thus, rather than interacting with ethanol's pharmacological effects, NTX may act on a biochemical substrate that modulates behavioral output related to responding for or consuming preferred solutions. These effects of NTX may be similar to the rate-dependent effects of amphetamine. Amphetamine has been shown to increase low rates of responding and decrease high rates of responding (Kelleher and Morse, 1968). NTX, like amphetamine, may be acting to decrease the high rates of responding engendered by the solutions. Responding for oral fluid deliveries, in some studies, was sensitive to the rate-dependent effects of amphetamine (Carroll, 1984; Slawecki and Samson, 1996). In conditions where NTX appeared to have selective effects on a particular behavior, the animals were performing those behaviors at a high frequency. For example, in rats, NTX reduced feeding from a palatable diet, but not from a normal chow diet (Apfelbaum and Mandenoff, 


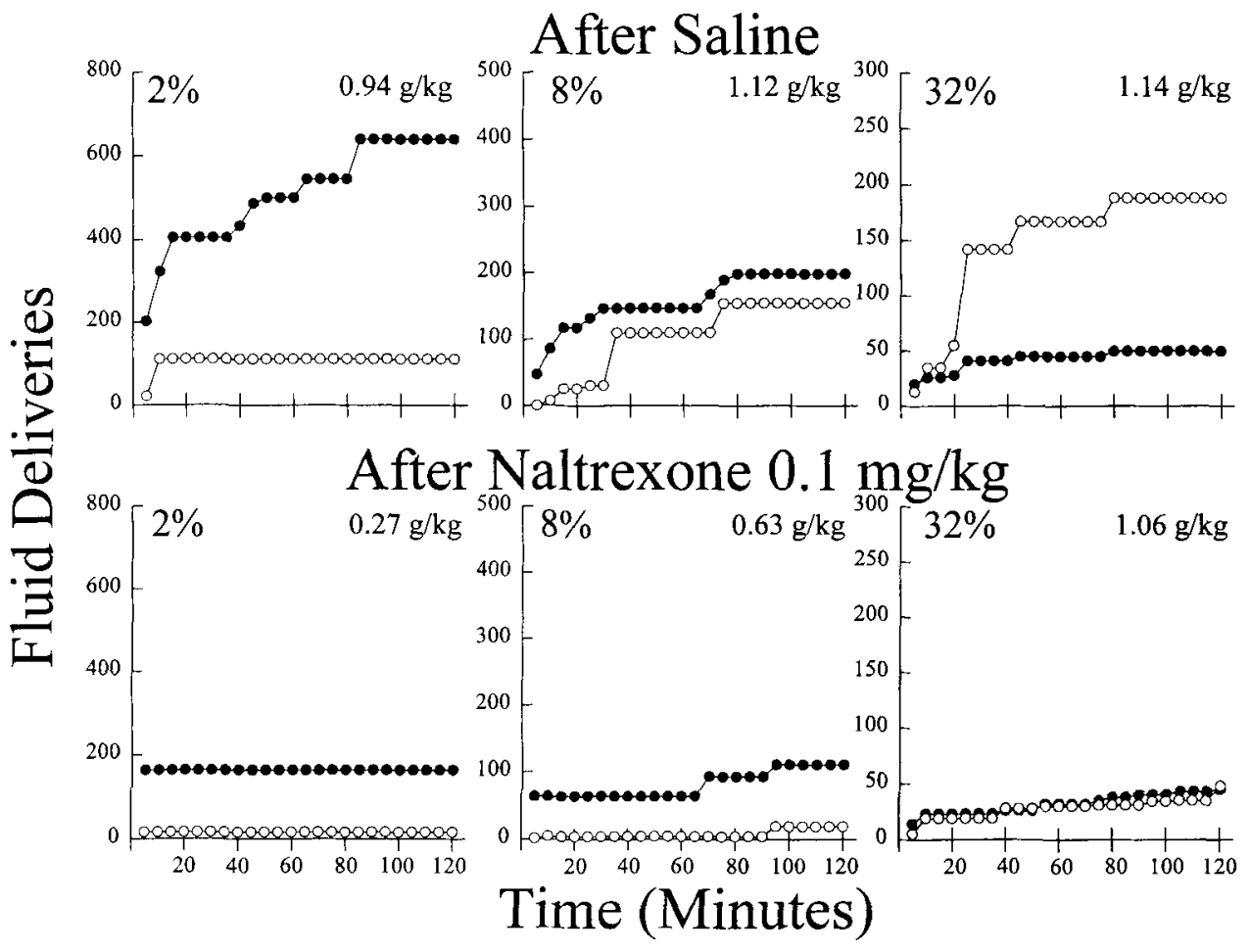

Fig. 5. (Top) Cumulative fluid deliveries for $2 \%$ (left), $8 \%$ (middle), or $32 \%$ (right) ethanol (O) and water (O) after saline injection for a representative monkey (MDG) during the 2-hr session. (Bottom) Cumulative fluid deliveries for $2 \%$ (left), $8 \%$ (middle), or $32 \%$ (right) ethanol $(O)$ and water $(O)$ after 0.1 $\mathrm{mg} / \mathrm{kg}$ naltrexone. The total ethanol intakes $(\mathrm{g} / \mathrm{kg})$ are shown in the upper right corner of each panel.
1981). However, the rate of feeding from the palatable diet was more than twice that of the normal chow diet. In another study, naloxone suppressed saccharin drinking only at the saccharin concentration that maintained almost twice the amount of behavior as that maintained by other saccharin concentrations (Lynch and Libby, 1983). Furthermore, choice procedures, such as the one used in our experiment, may be more sensitive to the rate-decreasing effects of NTX. For example, when multiple diets were examined in different choice combinations, the NTX dose that reduced the consumption of a particular diet varied through a $10-100$-fold dose range depending on the concurrently available diet (Giruado et al., 1993). However, in addition to decreasing high rates of responding, amphetamine also increases low rates of responding. NTX appears to decrease the occurrence of high frequency behavior without increasing low frequency behavior. Thus, NTX may influence behaviors differently from the manner suggested by the concept of rate dependence of the amphetamine type.

An alternative explanation for these observations, NTX may be inducing an aversive interoceptive state, such as nausea, that is incompatible with responding for or consuming solutions. Several laboratories have shown that NTX produces conditioned place or taste aversions (Leshem, 1984; Lett, 1985; Mucha and Herz, 1985; Parker et al., 1992; Stolerman et al., 1978). For instance, at the same pretreatment time as in the present study, $0.32 \mathrm{mg} / \mathrm{kg}$ NTX produced a conditioned taste aversion in rhesus monkeys (Williams and Woods, 1998). If this explanation is correct, we might expect the animals to cease all respond- ing for the solutions. The cumulative record data showed that responding for the solutions was decreased only after the first 5-min bin. However, there are a couple reasons why the animals may continue to respond for the solutions at the beginning of the session. First, at the NTX doses we used, the aversive interoceptive state may be mild before consuming the solutions, and the act of consuming several fluid deliveries at the beginning of the session may potentiate the aversive state that causes the monkeys to stop responding. Second, the stimulus control may be strong enough to engender some responding at the beginning of the session even in the presence of an aversive interoceptive state. Because these monkeys have extensive histories of oral-reinforced responding, the experimental session is associated with many stimuli such as the computer beep at the start of the session, the lights above the spouts, and the clicking of solenoids as the fluids are delivered.

The ethanol/NTX interaction is not similar to that of an opioid agonist/competitive antagonist interaction. Williams et al. (1998) addressed this issue by using $4 \%$ ethanol, which maintained less responding than the peak of the concentration-effect curve but also maintained a greater ethanol intake in grams per kilogram $(\mathrm{g} / \mathrm{kg})$. In that experiment, responding for ethanol after NTX pretreatment failed to increase in a manner that would indicate a competitive interaction between ethanol and NTX. In the present experiment, NTX was tested when the monkeys had access to a much higher ethanol concentration, $32 \%$, which maintained fewer fluid deliveries than the concurrently available water. NTX reduced only the water fluid deliveries, and the ethanol fluid deliveries and ethanol 
intake did not increase to compensate for the presumed receptor antagonism. An alternative argument, ethanol intake may not need to increase because the intake after NTX injection continued to be quite high $(1.5 \mathrm{~g} / \mathrm{kg})$. However, if NTX is competitively blocking endogenous opioid activity induced by ethanol intake, it should be necessary to increase ethanol intake. In studies using monkeys responding for intravenous opioid agonists, the administration of opioid antagonists caused responding for the agonists to increase at some available agonist doses and rightward shifts in the dose-effect curves were observed (Rowlett et al., 1998; Winger et al., 1992).

The ethanol concentration-effect curve shows that, at high concentrations ( $16 \%$ and $32 \%$ ), ethanol fluid deliveries were less than those of the concurrently available water. Although the ethanol fluid deliveries decreased as ethanol concentration increased, the ethanol intake failed to decrease below $1 \mathrm{~g} / \mathrm{kg}$. The ethanol intake was approximately the same for ethanol concentrations from $4 \%$ to $32 \%$, indicating that the monkeys may have been titrating their ethanol intake. An alternative explanation is that the taste of ethanol becomes aversive at high concentrations and the increased water deliveries might serve to dilute the strong taste of the ethanol (Meisch and Stewart, 1994). Thus, taste factors, rather than ethanol's pharmacological effects, may determine the shape of the ethanol concentration-effect curve. It may be coincidental that ethanol intake $(\mathrm{g} / \mathrm{kg})$ remained fairly constant across ethanol concentrations. The increased water responding may also be a form of adjunctive behavior. It is possible that some properties of high ethanol concentrations facilitate the development of responding for water. However, adjunctive behavior is usually produced in conditions where a reinforcer is delivered on an intermittent or infrequent schedule (Falk, 1998). This type of reinforcement schedule was not present in the oral self-administration paradigm.

In conclusion, the effects of NTX depend on the experimental conditions. NTX selectively reduces the fluid deliveries of the solution that maintained the greater amount of responding. Also, we provided further evidence that the ethanol/NTX interaction is not that of a classical opioid agonist/antagonist interaction. The data indicate that NTX either affects the properties related to responding for (or consuming) solutions or NTX induces an aversive interoceptive state that is incompatible with consummatory behaviors.

\section{REFERENCES}

Apfelbaum M, Mandenoff A (1981) Naltrexone suppresses hyperphagia induced in the rat by highly palatable diet. Pharmacol Biochem Behav 15:89-91.

Carroll ME (1984) Effects of pentobarbital and d-amphetamine on oral phencyclidine self-administration in rhesus monkeys. Pharmacol Biochem Behav 20:137-143.
Falk JL (1998) Solvay Award address: Drug abuse as an adjunctive behavior. Drug Alcohol Depend 52:91-98.

Froehlich JC, Harts J, Lumeng L, Li T-K (1990) Naloxone attenuates voluntary ethanol intake in rats selectively bred for high ethanol preference. Pharmacol Biochem Behav 35:385-390.

Giruado SQ, Grace MK, Welch CC, Billington CJ, Levine AS (1993) Naloxone's anorectic effect is dependent upon the relative palatability of food. Phanmacol Biochem Behav 46:917-921.

Kelleher RT, Morse WH (1968) Determinants of the specificity of behavioral effects of drugs. Ergebn Physiol Biol Chemie 60:1-56.

Kornet M, Goosen C, Van Ree JM (1991) Effect of naltrexone on alcohol consumption during chronic alcohol drinking and after a period of imposed abstinence in free-choice drinking rhesus monkeys. Psychopharmacology 104:367-376.

Leshem M (1984) Suppression of feeding by naloxone in rat: A doseresponse comparison of anorexia and conditioned taste aversion suggesting a specific anorexic effect. Psychopharmacology 82:127-130.

Lett BT (1985) The painlike effect of gallamine and naloxone differs from sickness induced by lithium chloride. Behav Neurosci 99:145-150.

Lynch WC, Libby L (1983) Naloxone suppresses intake of highly preferred saccharin solutions in food deprived and sated rats. Life Sci 33:1909_ 1914.

Marfaing-Jallat P, Miceli D, Le Magnen J (1983) Decrease in ethanol consumption by naloxone in naive and dependent rats. Pharmacol Biochem Behav 18:537-539.

Meisch RA, Henningfield J, Thompson T (1975) Establishment of ethanol as a reinforcer for rhesus monkeys via the oral route: Initial results. Adv Exp Med Biol 59:323-342.

Meisch RA, Stewart RB (1994) Ethanol as a reinforcer: A review of laboratory studies of nonhuman primates. Behav Pharmacol 5:425-440.

Mucha RF, Herz A (1985) Motivational properties of kappa and mu opioid receptor agonists studied with place and taste preference conditioning. Psychopharmacology 86:274-280.

Myers RD, Borg S, Mossberg R (1986) Antagonism by naltrexone of voluntary alcohol selection in the chronically drinking macaque monkey. Alcohol 3:383-388.

Parker LA, Maier S, Rennie M, Crebolder J (1992) Morphine- and naltrexone-induced modification of palatability: Analysis by the taste reactivity test. Behav Neurosci 106:999-1010.

Rowlett JK, Wilcox KM, Woolverton WL (1998) Self-administration of cocaine-heroin combinations by rhesus monkeys: Antagonism by naltrexone. J Pharmacol Exp Ther 286:61-69.

Samson HH, Doyle TF (1985) Oral ethanol self-administration in the rat: Effect of naloxone. Pharmacol Biochem Behav 22:91-99.

Slawecki CJ, Samson HH (1996) Effect of amphetamine on behavior maintained by sucrose: Interaction of reinforcement schedule and food restriction. Pharmacol Biochem Behav 54:595-600.

Stolerman IP, Pilcher CWT, D'Mello GD (1978) Stereospecific aversive property of narcotic antagonists in morphine-free rats. Life Sci 22:17551762.

Williams KL, Winger G, Pakarinen ED, Woods JH (1998) Naltrexone reduces ethanol- and sucrose-reinforced responding in rhesus monkeys. Psychopharmacology 139:53-61.

Williams KL, Woods JH (1999) Conditioned effects produced by naltrexone doses that reduce ethanol-reinforced responding in rhesus monkeys. Alcohol Clin Exp Res 23:708-715.

Winger G, Skjoldager P, Woods JH (1992) Effects of buprenorphine and other opioid agonists and antagonists on alfentanil- and cocainereinforced responding in rhesus monkeys. J Pharmacol Exp Ther 261: 311-317. 